\title{
Research Article \\ Effect of Friction Model and Tire Maneuvering on Tire-Pavement Contact Stress
}

\author{
Haichao Zhou, ${ }^{1}$ Guolin Wang, ${ }^{1}$ Yangmin Ding, ${ }^{2}$ Jian Yang, ${ }^{1}$ Chen Liang, ${ }^{1}$ and Jing Fu ${ }^{1}$ \\ ${ }^{1}$ School of Automotive and Traffic Engineering, Jiangsu University, Jiangsu 212013, China \\ ${ }^{2}$ School of Engineering, Rutgers-The State University of New Jersey, NJ 08854, USA
}

Correspondence should be addressed to Haichao Zhou; haichaozhou999@163.com

Received 9 January 2015; Accepted 20 May 2015

Academic Editor: Katsuyuki Kida

Copyright (C) 2015 Haichao Zhou et al. This is an open access article distributed under the Creative Commons Attribution License, which permits unrestricted use, distribution, and reproduction in any medium, provided the original work is properly cited.

This paper aims to simulate the effects of different friction models on tire braking. A truck radial tire (295/80R22.5) was modeled and the model was validated with tire deflection. An exponential decay friction model that considers the effect of sliding velocity on friction coefficients was adopted for analyzing braking performance. The result shows that the exponential decay friction model used for evaluating braking ability meets design requirements of antilock braking system (ABS). The tire-pavement contact stress characteristics at various driving conditions (static, free rolling, braking, camber, and cornering) were analyzed. It is found that the change of driving conditions has direct influence on tire-pavement contact stress distribution. The results provide the guidance for tire braking performance evaluation.

\section{Introduction}

Various simulation studies $[1,2]$ and experiment results $[3,4]$ have shown that tire-pavement contact stress has a great influence on vehicle handling and stability. The contact stress between tire and road surface is affected by parameters, such as tire load, velocity, pavement characteristics, and the slip rate. Although the contact stress can be evaluated by adhesion coefficient between tire and road surface, the classic Coulomb friction model is not enough to simulate the friction response of rubber elastomeric [5]. Savkoor [6] proposed a rubber sliding friction coefficient formula which effectively takes into consideration the friction coefficient with velocity, pointing out that the friction coefficient increases with increasing slip velocity, and then, with the slip velocity increasing, the coefficient of friction begins to decline. Dorsch et al. [7] found that there is a nonlinear relationship between friction and parameters, like tire contact stress, slip velocity, and temperature parameters. Ma et al. [8], based on Savkoor model, studied the influence of rubber properties and pavement on sliding friction factors. Li et al. [9] presented a unified friction model from the test data, which characterizes the different tread rubber friction behavior. The numerical results correspond to the experimental results.
ABS is a vehicle safety control system with nonslip, antilock advantages. Generally speaking, the tread poses sliding and rolling, respectively, in forward motion and along the circumferential direction under ABS [10]. Therefore, a simple simulation of the tire slip is not a true reflection of braking performance. And, in the finite element analysis, tirepavement was usually simulated by Coulomb model; however, because of the viscoelastic properties of the model itself and Coulomb rubber material limitations, the simulation method cannot accurately reflect the braking state any more.

In this study, the effects of different friction models on tire braking force were investigated. It is found that by using an exponential decay friction model, in which the braking angler can be varied, the maximum braking force can be obtained when the tire reaches critical tire slip. This study also simulated the distribution of different contact stress conditions under various tire driving conditions (static, free rolling, braking, camber, and cornering), which provides guidance for braking performance evaluation.

\section{Tire FEM Model and Model Verification}

2.1. Numerical Model of Rubber Material. In this paper, the model of 295/80R22.5 radial tire was built under the 


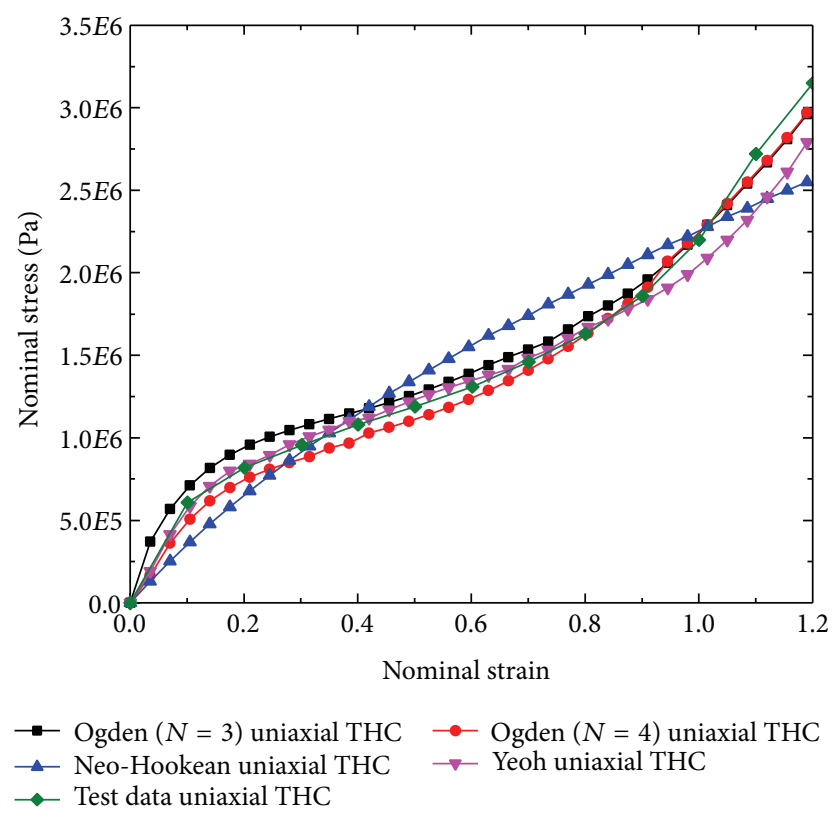

FIgURE 1: The experiment and fitting curve of undertread rubber.

inflation pressure $900 \mathrm{kPa}$, with a load of $35.5 \mathrm{kN}$. The rubber materials can endure large elastic deformation, because of the high linearity of the stress-strain relationship. Rubber is an isotropic hyperelastic material and can be described by the Ogden, the Neo-Hookean, and the Yeoh model [11]. However, the Yeoh model differs from other models in that it only depends on the first strain invariant; thus it can be used to fit various models of deformation with the uniaxial tension data.

Yeoh model is in the following equation:

$$
W=C_{10}\left(I_{1}-3\right)+C_{20}\left(I_{1}-3\right)^{2}+C_{30}\left(I_{1}-3\right)^{3},
$$

where $I_{1}$ is the first invariant of strain and $C_{10}, C_{20}$, and $C_{30}$ are the material constants, which can be determined from the experimental data in which the rubber specimen is subjected to uniaxial tension [12]. As shown in Figure 1, several models can be used to describe the undertread elastic mechanical performance in the uniaxial tension experiment. It is declared that the Yeoh model is adopted in the finite element analysis of rubberlike elastomers.

2.2. Finite Element Model of Cord-Rubber Composite. In this study, the cord-rubber composite is modeled with rebar layers, such as belts and carcass. Rebar stiffness superimposed on the solid rubber stiffness has been widely used to model tires $[2,3]$. The steel wires are considered an isotropic material with Young's modulus $2000 \mathrm{GPa}$, Poisson's ratio 0.28 , and mass density $7900 \mathrm{~kg} / \mathrm{m}^{3}$. Reinforcement materials in carcass, belts, and enhancement plies are modeled using rebar layer in surface element SFM3D4R, which is a 4 nodded quadrilateral element. The bead is defined as isotropic material described by C3D8R element.

2.3. Mesh Generation and Element Selection. The 295/80R22.5 tire mainly includes tread, shoulder, sidewall, carcass, inner, belt, apex, bead, and so forth. Tread, shoulder, sidewall, inner, and apex are composed of pure rubber with different hardness. Belt, carcass, and bead are modeled as a single layer or multilayer cord-rubber composites. The static tire simulation is divided into three substeps.

First, a two-dimensional tire mesh is generated. The axisymmetric model shown in Figure 2(a) includes 843 nodes and 768 elements. Second, the INP file of the axisymmetric model was imported to ABAQUS which is used to simulate the mounting procedure of the tire and rim, along with the inflation of the tire. Third, SYMMETRIC MODEL GENERATION was used to generate the three-dimensional (3D) tire model shown in Figure 2(b). Meanwhile the results from the axisymmetric analysis are transferred to the $3 \mathrm{D}$ model. In order to take into account the accuracy and efficiency, the tire mesh was divided into $2.5^{\circ} \times 60+1^{\circ} \times 60+2.5^{\circ} \times 60$ segments as depicted in Figure 2(b). In the tire model, C3D8H and SFM3D4R elements were used to define the rubber material and steel cord, respectively.

2.4. Boundary Conditions. The footprint analysis includes the following three major steps:

(1) Apply inflation pressure (900 kPa in this study).

(2) Establish surfaces contact between tire and rim and tire and road. The penalty method was invoked for this purpose.

(3) Simulate the static deflection, move the road surface to special position until a given force, for example, rated load, was exerted on the tire.

2.5. Model Validation. After the 295/80R22.5 tire is inflated to $900 \mathrm{kPa}$ and is subjected to the vertical load of $35.5 \mathrm{kN}$, it is shown from Figure 3(a) that the tire is in inflated state with no-load. And the inflation sectional width, $B$, and the inflation outer diameter, $D$, are obtained and listed in Table 1. As shown in Figure 3(b), the largest deformed section width $W_{d}$ in the lowest cross section of the tire is obtained. The measured and computed values of $W_{d}$ are given in Table 1 . To validate the tire model, the same tire is tested on the static loading machine, the MTM-2 tire testing machine, with a pressure-sensing pad, as indicated in Figure 4. During the test, the axis can only move vertical (up or down), but the pad can move longitudinally or transversely. The length and width of contact patch are denoted as $L$ and $T$, respectively. Meanwhile, the area of tire footprint, $A$, is also shown in Table 1. Figure 5 shows the comparison of the simulated load-deflection characteristics with the measurement. It can be seen from Figure 5 that, with the increase of vertical displacement, the vertical load increases nonlinearly. The predicted curve is in agreement with the measured data with $5.9 \%$ error.

\section{Rolling Tire Model}

The study employs Arbitrary Lagrangian Eulerian (ALE) description to simulate steady state rolling. ALE decomposes the tire deformation into material deformation and rigid body motion. Tire material deformation was used by 


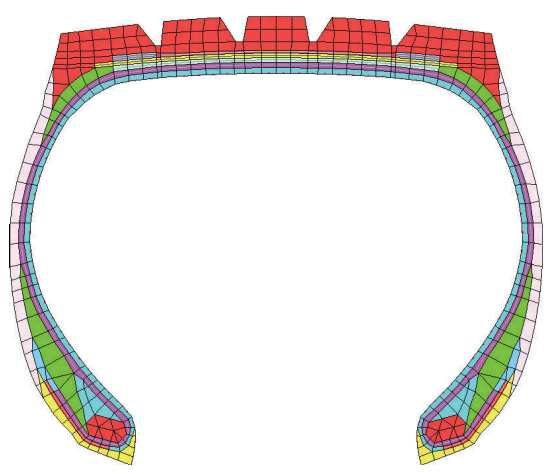

(a)

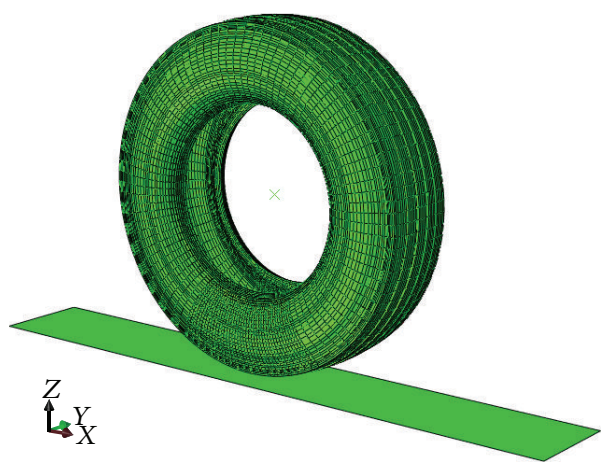

(b)

Figure 2: (a) Axisymmetric FEM model. (b) Three-dimensional FEM model.

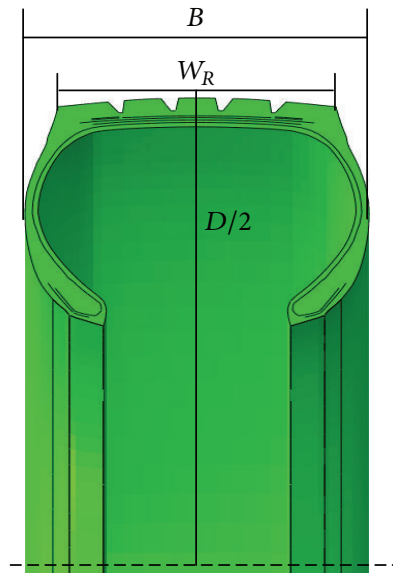

(a)

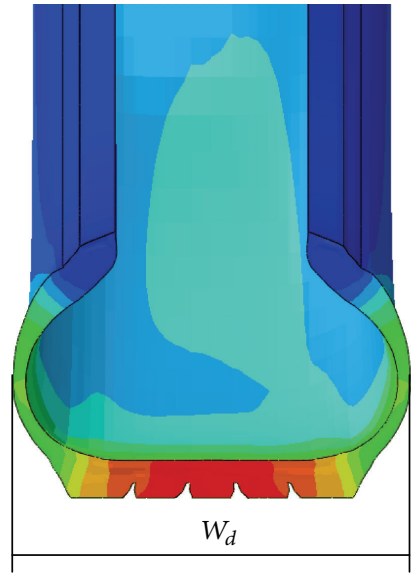

(b)

FIgURE 3: (a) Section of tire inflated state. (b) Deformation of the lowest section of tire.

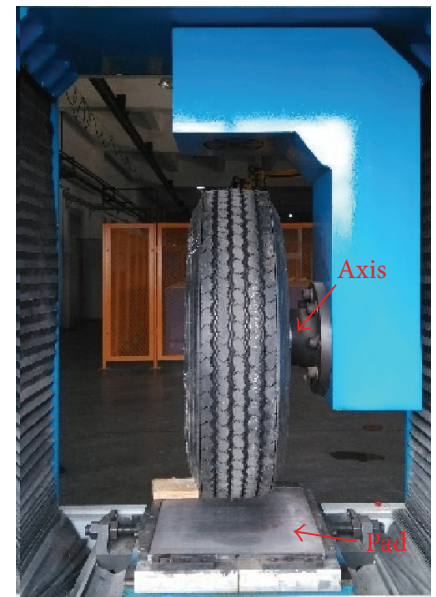

FIGURE 4: Static loading test.

Lagrangian method, and the tire rigid body motion was described by Euler method. Compared with the traditional tire rolling analysis, this method considers tire rolling and sliding and can effectively obtain the total force and torque

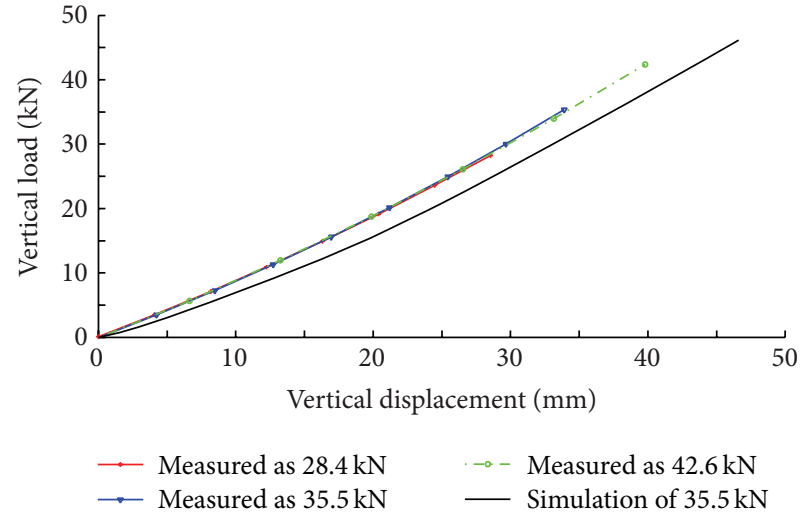

Figure 5: Comparison of the simulated load-deflection characteristics with the measurement.

characteristics of the tire under different driving conditions. In addition, this method takes into account the effect of friction, inertia effects, and viscoelastic effects of the material. However, there is a need to refine the mesh in the tire contact area. 
TABLE 1: Comparison of the predicted results with measurement. (Inflation section width $B$, inflation outer diameter $D$, inflation tread width $W_{R}$, the largest deformed section width $W_{d}$, the length and width of the contact patch denoted as $L$ and $T$, and the area of tire footprint $A$.)

\begin{tabular}{lccccccc}
\hline & $B(\mathrm{~mm})$ & $D(\mathrm{~mm})$ & $W_{R}(\mathrm{~mm})$ & $W_{d}(\mathrm{~mm})$ & $L(\mathrm{~mm})$ & $T(\mathrm{~mm})$ & $A(\mathrm{~mm})$ \\
\hline Measured results & 296.2 & 1042.1 & 234.5 & 326.5 & 264.3 & 228.5 & 455.2 \\
Predicted results & 295.2 & 1041.2 & 234.1 & 324.6 & 267.7 & 230.1 & 460.7 \\
\hline
\end{tabular}

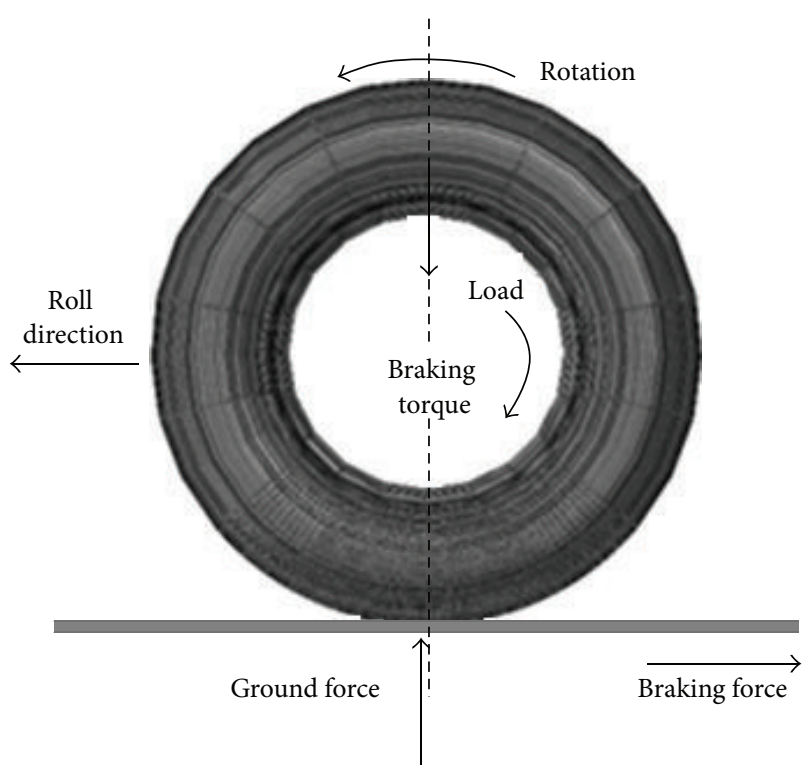

Figure 6: Illustration of tire braking simulation.

The slip ratio is calculated by

$$
S=\frac{V-r_{k c} \omega}{V} \times 100 \%
$$

where $r_{k c}$ is rolling radius, $V$ is velocity, and $\omega$ is tire rolling angular velocity.

The steady state of rolling tire is between the state of braking and acceleration. By changing the angular velocity, the torque or the braking force between the tire and the road is controlled to determine whether the tire reaches free rolling state. Figure 6 shows the illustration of the rolling tire model. When the tire reaches free rolling state, the tire slip ratio is zero. At this moment, the relation between velocity and the rotation angular velocity is as follows:

$$
V=r_{k c} \cdot \omega
$$

At this point, when reducing or increasing the angular velocity, the braking or acceleration condition occurs, and the interaction force between the tire and the surface is nonzero. Therefore, the steady state rolling condition can be adjudged by checking whether tire braking force or torque is zero. It can be seen from Figure 7 that, when the rolling speed reaches $50 \mathrm{~km} / \mathrm{h}$, the angle velocity is $27.3146 \mathrm{rad} / \mathrm{s}$ and the tire reaches steady state.

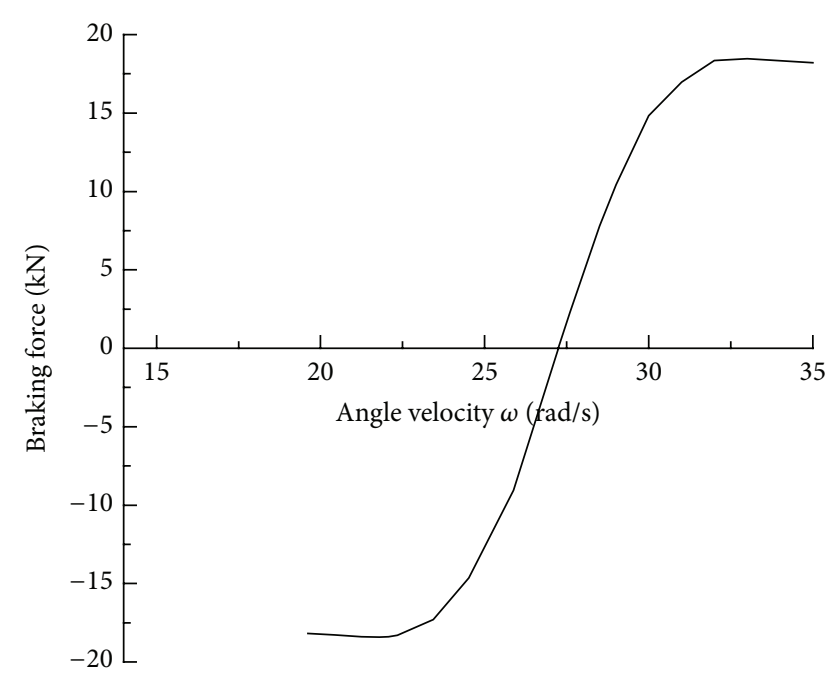

FIGURE 7: The relationship between braking force and angle velocity $(V=50 \mathrm{~km} / \mathrm{h})$.

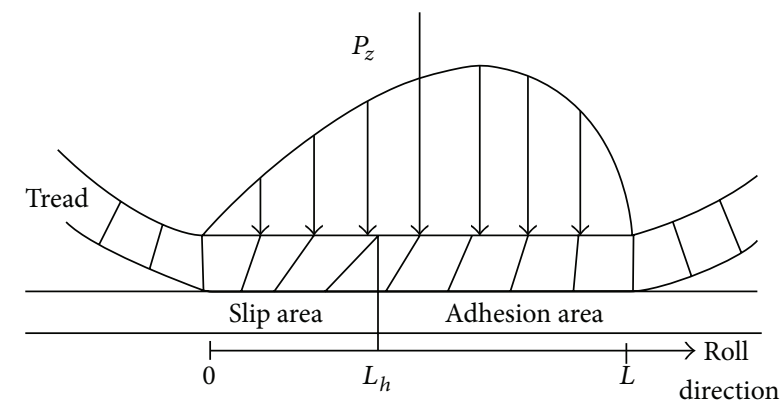

FIGURE 8: Tire contact patch distribution during tire rolling.

\section{Tire-Pavement Friction Model}

Tire-pavement friction model has a direct impact on the study of tribology and tire mechanical properties. Due to the viscoelastic properties of tire rubber, the tire-pavement contact area was divided into two regions, the slip area and adhesion area as shown in Figure 8 , where $P_{z}$ is tire inflate pressure, $L$ is the length of tire contact region, and $L_{h}$ is the division position of the two region. In the adhesion area, there is no relative slip between the tread and the pavement surface. While in the rear of the contact patch, the adhesive force exceeds the maximum friction force that the surface can bear; thus the relative slip occurs [13].

To take full account of rubber friction and the braking characters of a rolling tire, this study uses Cullen friction model and exponential decay friction model in ABAQUS 


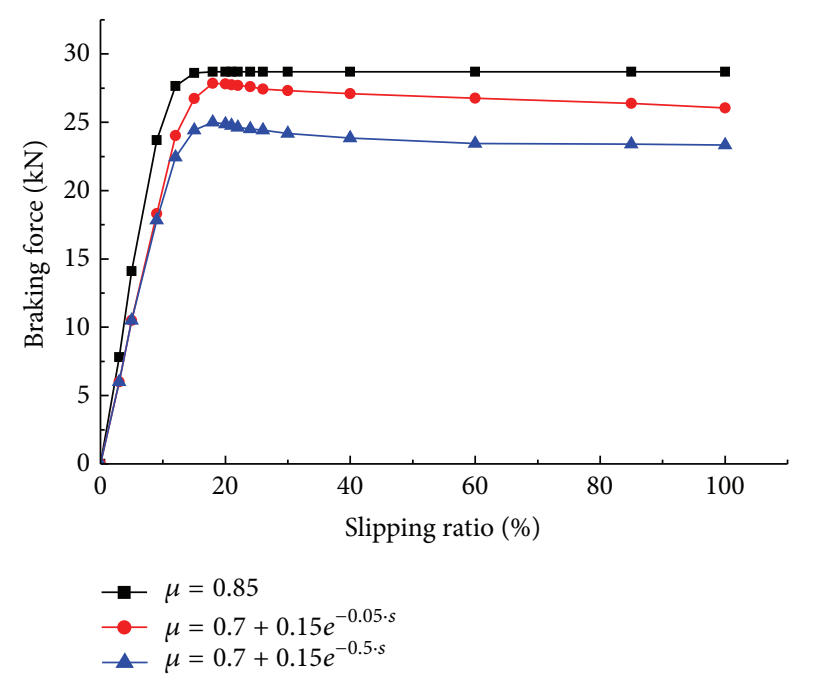

FIGURE 9: Braking force variation with different friction models.

to simulate contact area, where friction coefficient is used to represent the friction property in the contact area. The calculation formula of friction for Cullen is

$$
\tau_{\text {crit }}=\mu \times P_{z}
$$

where $\tau_{\text {crit }}$ is the critical shear stress; $\mu$ is the static friction coefficient; $P_{z}$ is the normal contact pressure.

The coefficient of friction model for exponential function of sliding ratios is as follows:

$$
\mu=\mu_{k}+\left(\mu_{s}-\mu_{k}\right) e^{-d_{c} \cdot s},
$$

where $\mu_{k}$ is kinetic friction coefficient at the highest sliding velocity, $\mu_{s}$ is static friction coefficient at the onset of sliding (zero sliding velocity), $s$ is sliding velocity, and $d_{c}$ is userdefined decay coefficient [14]. Equation (5) describes how the coefficient of friction between two contact bodies changes from static to dynamic process. For the contact between the tire and pavement surface, $\mu_{s}$ is more related to the surface microtexture, while $d_{c}$ is highly dependent on surface macrotexture [15]. In this paper, the different decay coefficient $d_{c}$ is selected as 0.5 and 0.05 , respectively, to represent the friction characteristics of pavement surface with poor and good macrotextures, respectively. The static friction coefficient is defined as 0.85 [16], and the kinetic friction coefficient is 0.7 . The tire speed is $50 \mathrm{~km} / \mathrm{h}$. For vehicle with certain mass, the greater the braking force, the greater the braking deceleration and the shorter the braking distance. So the braking force can be used to evaluate vehicle braking. Therefore, this paper uses braking force to evaluate the influence of different friction models on tire grounding performance.

Figure 9 shows that all the friction models are able to get the critical slip friction coefficient corresponding to peak friction force. It can be seen that the braking force reaches its maximum when the slip ratio is around $18 \%$ (the critical slip coefficient). However, when the slip coefficient is less than the critical slip friction coefficient, the braking force increases and becomes larger. In this case, the tire contact area is in the partial slip state. Once the slip ratio exceeds the critical slip coefficient, the tire contact area changes from partial slip to complete slip. But the contact area remains unchanged when Coulomb friction was used. While the use of the exponential decay model has a downward trend, the road performance attenuation coefficient has a significant effect on friction. The experimental tests from Al-Qadi and Yoo [14] also showed the same trend. It can be seen that, compared with Coulomb friction model, the exponential decay model is closest to the practical tire braking dynamic situation, which is also in line with the principle of the ABS system.

Figures 10 and 11, respectively, show tire contact stress and slip distribution of the three friction models under critical slip. It can be seen from these Figures that the type of friction model had no obvious impact on stress distribution and slip friction contact area. However, the type of friction model had a significant impact on the maximum stress and maximum ground slippage.

\section{Contact Stress Analysis under Different Working Conditions}

Figure 12 shows that when the tire is subjected to static loads, because of its convex tread arc and large sidewall deformation, the center of the tire tread contacts the surface first, leading to the maximum stress distribution on the center rib. Since the tread rubber was in extrusion, the tire longitudinal and transverse stresses are generated in contact area. In the roll direction, the contact stresses are in an antisymmetric state, and the stress value is negative in the front and positive in the transverse direction. The stress presents a vase-shaped distribution. Since the center of the contact area and shoulder pose a larger deformation in the transverse direction, there is relatively larger transverse stress on the ground. Owing to the vertical static load, the average contact stress in roll direction and in the axial direction is zero.

It can be seen from Figure 13 that when the tire is in a free rolling steady state, the resultant friction force is zero. Compared with the static state, the stress distribution and contact patch shape have no significant change, but the stress in transverse direction becomes asymmetric, and the stress distribution is mainly concentrated on the front contact region, and the center of the tire contact moved towards the leading edge. This is mainly because, during tire rolling, the fronts tread rubber contacts the surface first, and it deformed under the vertical load. Since the rubber is incompressible, the deformed front area moved towards the shoulder, but the rear rubber contracted because of extrusion from the center rib. When the tread gradually leaves the surface, the contact stress on the ground undergoes significant change. However, due to the centrifugal effect, the peak contact stress in the steady state rolling is much less than that of the stationary state. It can be concluded that, under free rolling, the decrease of contact stresses reduces the relative friction between the tire and the road surface; that is, rolling friction is less than the maximum static friction, thus helping to reduce tire rolling resistance. 


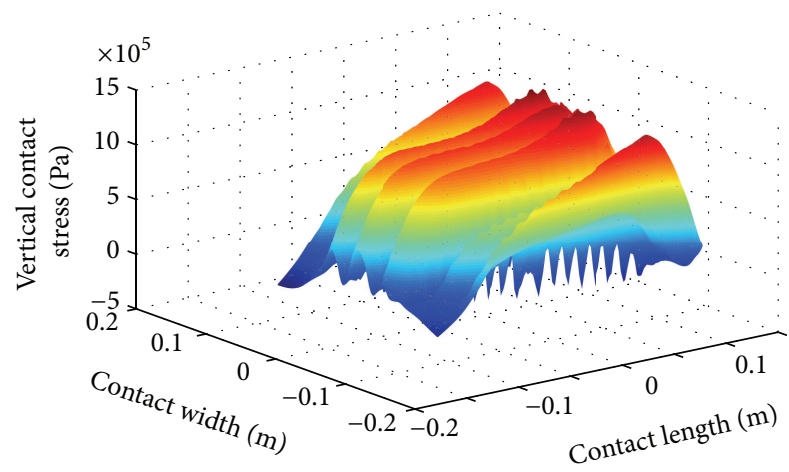

(a)

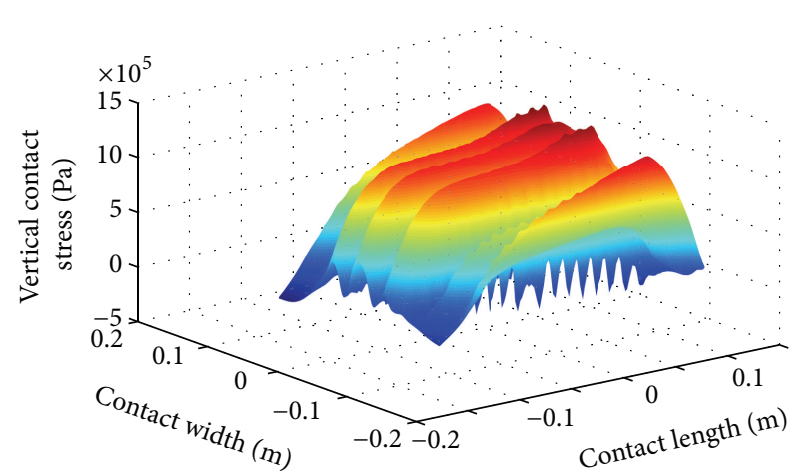

(b)

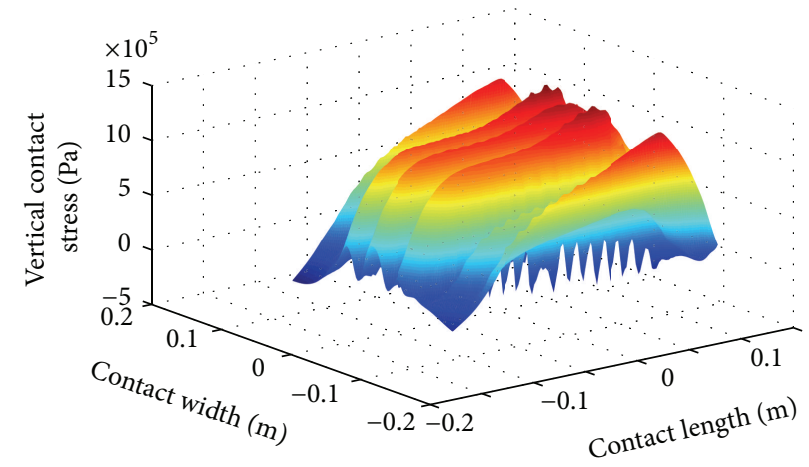

(c)

FigURE 10: Effects of friction model on vertical contact stress distribution at (a) $\mu=0.85$, max: $1.45 \times 10^{5} \mathrm{~Pa},(\mathrm{~b}) \mu=0.7+0.15 e^{-0.5 s}$, max: $1.43 \times 10^{5} \mathrm{~Pa}$, and (c) $\mu=0.7+0.15 e^{-0.05 s}, \max : 1.26 \times 10^{5} \mathrm{~Pa}$.

When braking or acceleration, the tire rotational angular velocity is either less than or greater than the steady state free rolling angular velocity, and the center of the tire rib generates a rolling torque, which results in the tire slip and adhesion. The only difference between the two conditions is a different direction of action. Therefore, the contact stress under braking is analyzed. Compared with the contact stress distribution under static state, the contact stress distribution under braking state (as shown in Figure 14) varied significantly and presents asymmetry. The stress in the front of the contact area was greater than that at the end part.

Compared with the stress distribution in static and free rolling state, contact stress tends to increase from three directions. In particular, the change of longitudinal contact stress is most obvious, from the raise at the front end and depression at the rear end, to raise at the entire contact area. The transverse stress is moved to the front end, and the longitudinal stress vector in the ground is no longer zero. There is a braking force between the tire and the road surface.

The camber angle, $\gamma$, which measures the camber of the tire plane with respect to the vertical, directly affects the performance of the tire. This study analyzed the contact stress distribution at the camber angle of $2^{\circ}$ under braking condition. As shown in Figure 15, at the presence of camber angle under the rolling condition, the contact stress moves to the direction of the camber angle, especially in the transverse direction, which is a significant change, but, in the roll direction, the stress distribution remains the same. The camber not only makes the tire shoulder deposit stress concentration, but also changes the maximum tire contact stress. The contact stress transits from the central contact area to the edge of the shoulder so that the contact stress is no longer symmetric. The camber also changes the contact length of the shoulder edge and increases stress values. Above all, the transverse stress has a significant change; the longitudinal stress changes the least. The above phenomena show that, to a certain extent, the existence of camber changes the contact point and the force imposed point, which directly affect grip and tire wear.

When the centerline plane of the tire and the wheel shifted a certain distance, this will produce a lateral force $F$ in the center of the tire along the transverse direction, coupled with the elastic deformation of the rubber; thus the tire is deformed, resulting in a deviation from the roll direction of the tire predetermined travel route. According to the tire axis system, the slip angle, $\alpha$, is measured from the contact center across the pavement to the tire roll direction. Figure 16 shows the contact stress distribution at $2^{\circ}$ slip angle under braking condition. It can be seen that the contact stress moves in the direction of the slip angle, and the maximum stress occurs at the inner side where the slip angle appears. The stress at the 

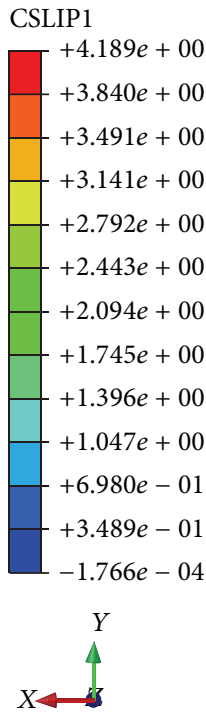

CSLIP1
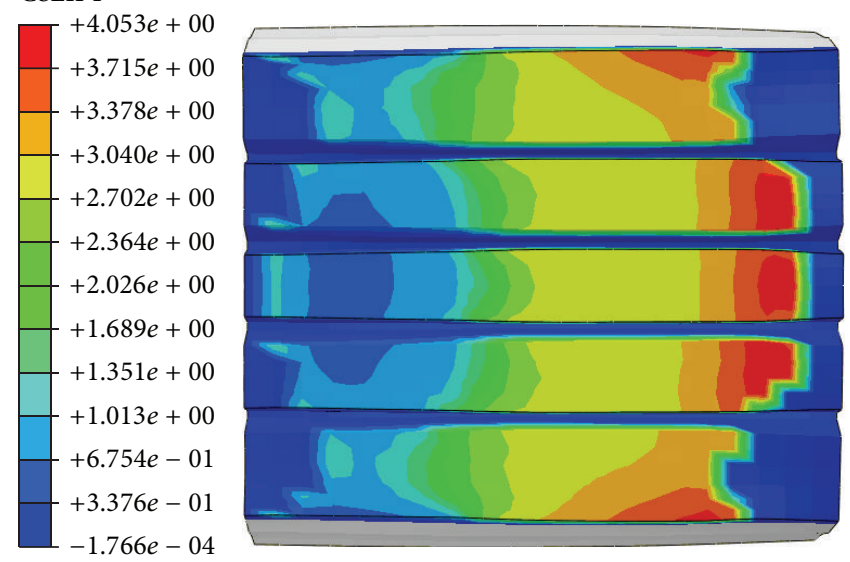
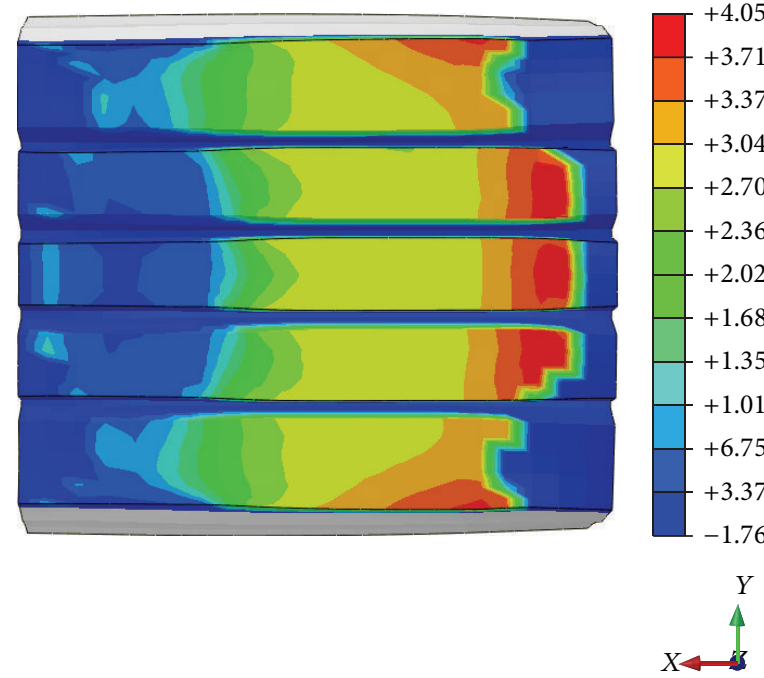

(a)

(b)

CSLIP1
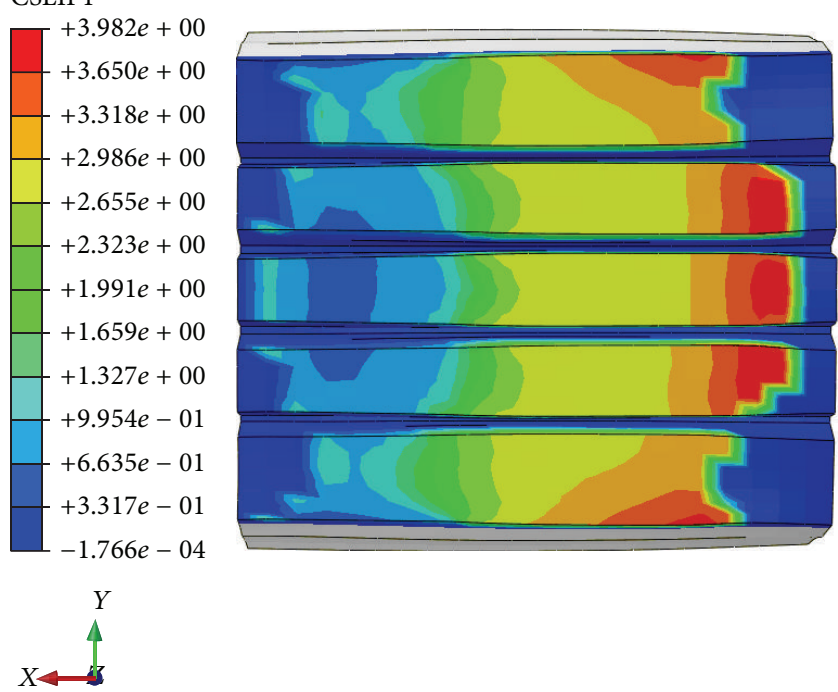

(c)

FIGURE 11: Effects of friction on contact area distribution at (a) $\mu=0.85$, (b) $\mu=0.7+0.15 e^{-0.5 s}$, and (c) $\mu=0.7+0.15 e^{-0.05 s}$.

inner side is much higher than that in the outer side of the tire, and the stress in the tire transverse direction is asymmetric. The above phenomena also shows the existence of slip angle changes the contact point and the force imposed point, which directly affect grip and tire wear.

Practically, a rolling tire possesses both camber angle and slip angle. Figure 17 shows the contact stress in such a working condition. It can be seen that the effects of camber on stress distribution are dominant. The contact stress at the edge of shoulder is higher than that in the center rib. Obviously, compared with the effects under camber angle and slip angle separately, the stress distribution under combined working conditions moves towards the edge of the tire and the stress value gap between tire shoulder and contact becomes larger.

\section{Conclusions}

(1) The tire-pavement contact friction models have a decisive influence on the maximum braking force. Compared with Coulomb friction model, the use of the exponential decay model is closer to the practical tire braking dynamic situation, which is also in line with the principle of the ABS system.

(2) In the static state and free rolling state, both the vertical and longitudinal stress show asymmetry of the contact stress in the transverse direction and the vertical stress predominant stress distribution, and the mean stress in the roll direction is zero. However, the transverse stress in the contact area becomes 


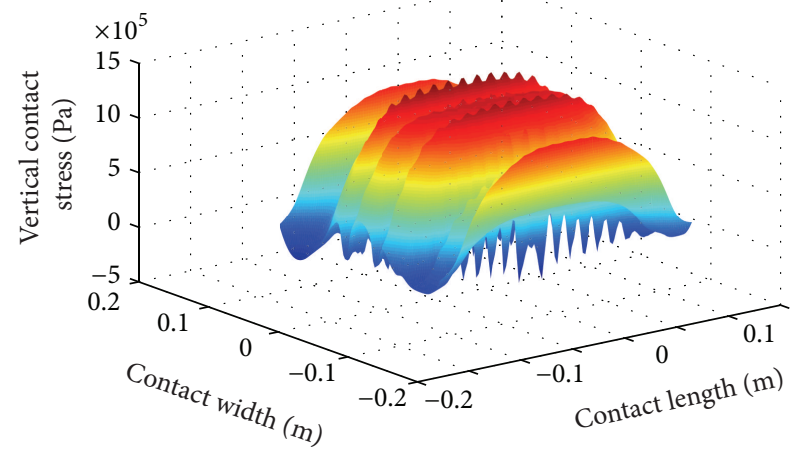

(a)

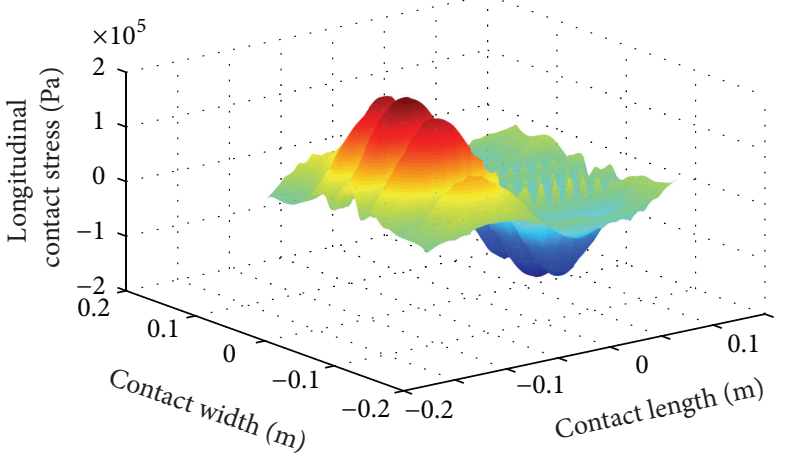

(b)

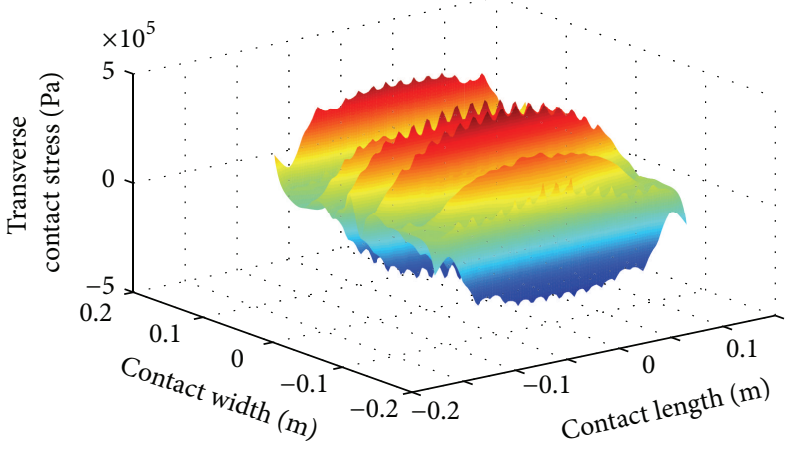

(c)

FIGURE 12: Contact stress distribution under static state.

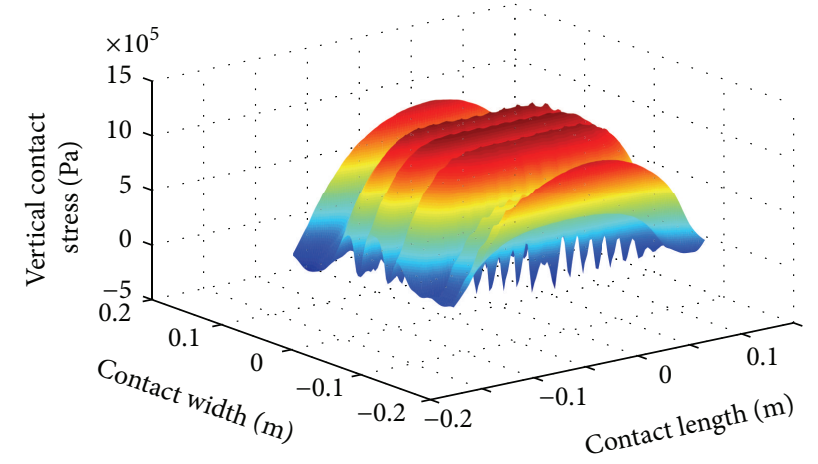

(a)

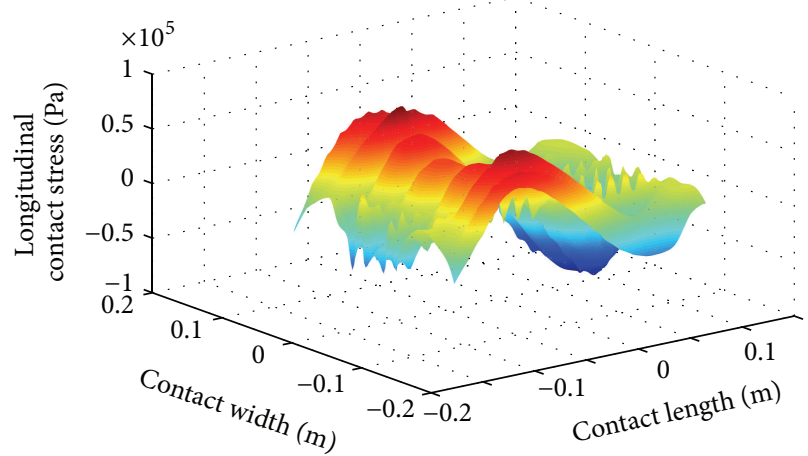

(b)

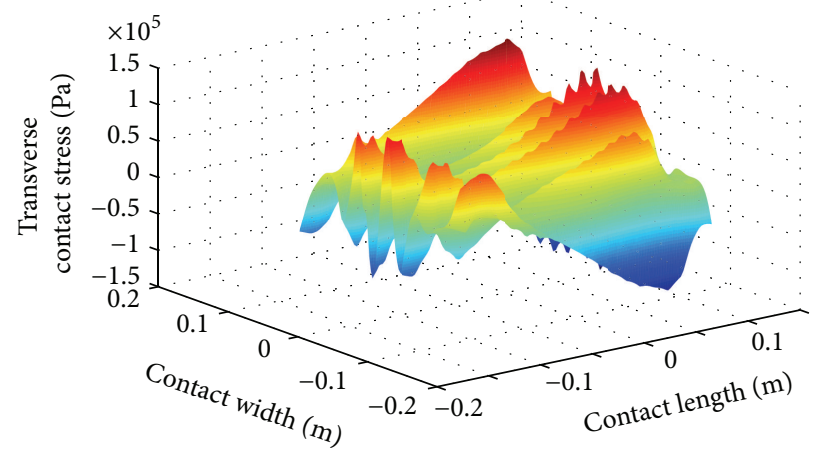

(c)

FIGURE 13: Contact stress distribution under steady free rolling. 


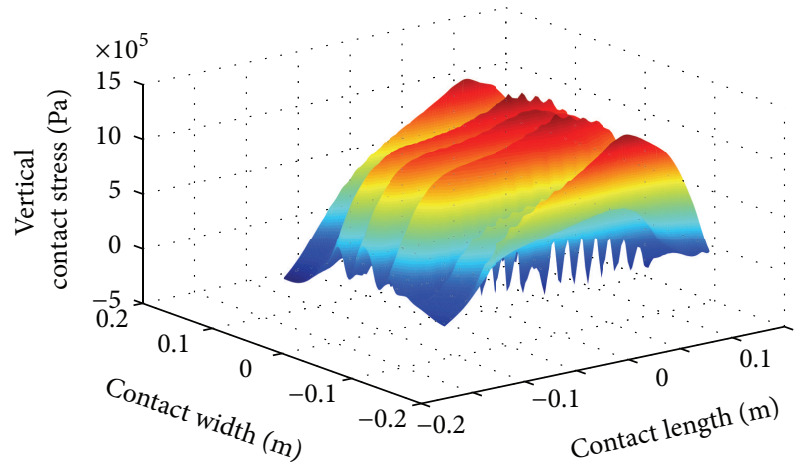

(a)

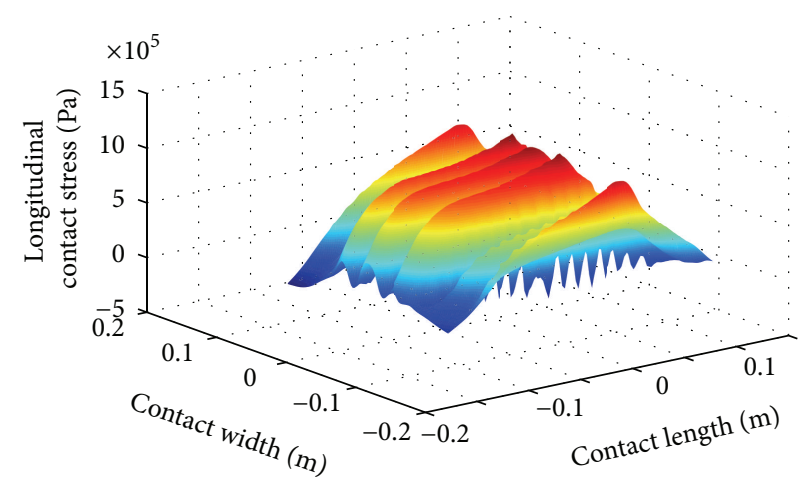

(b)

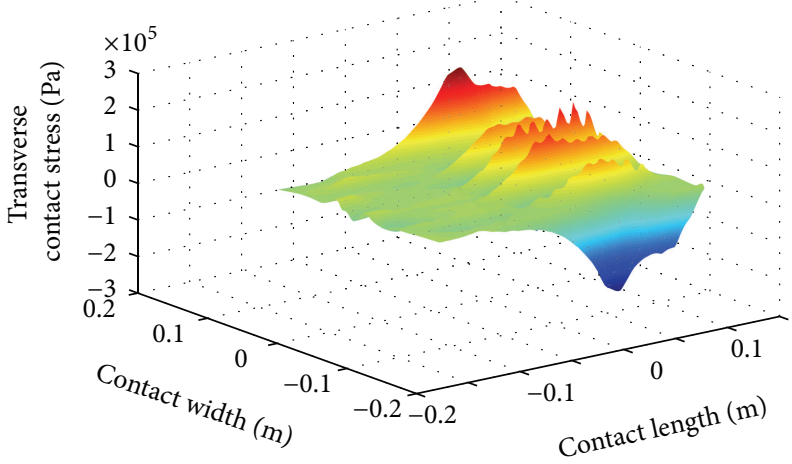

(c)

FIGURE 14: Contact stress distribution under braking.

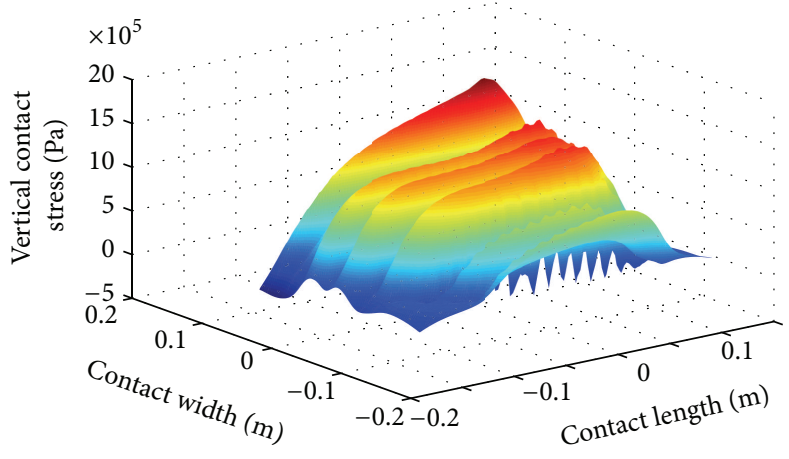

(a)

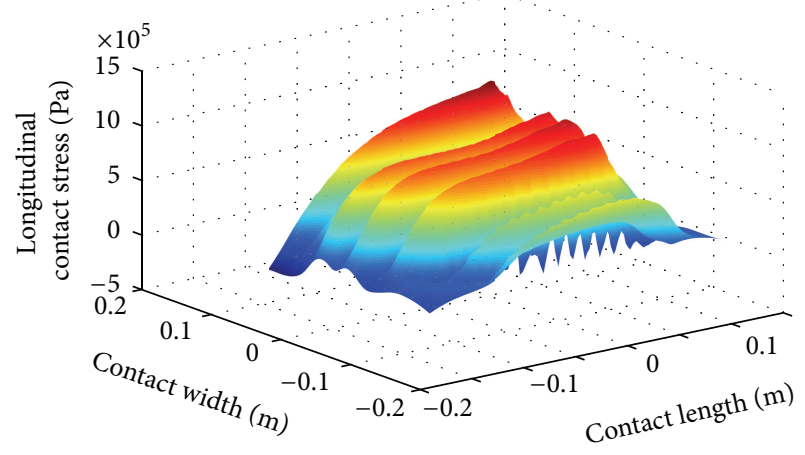

(b)

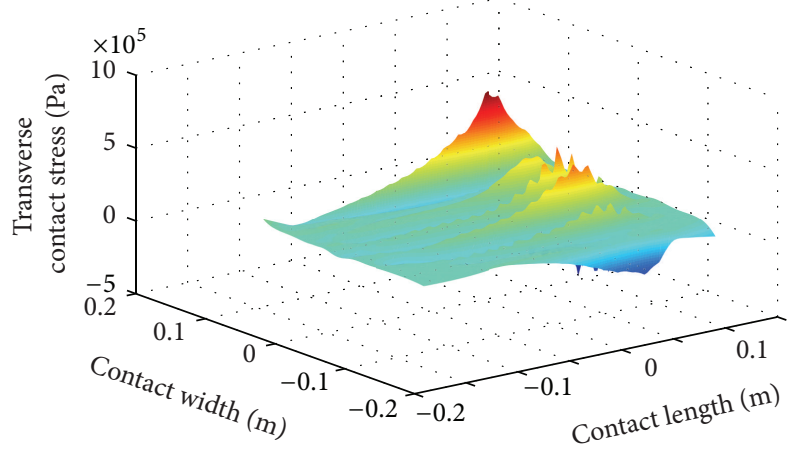

(c)

FIGURE 15: Contact stress distribution under braking condition with camber. 


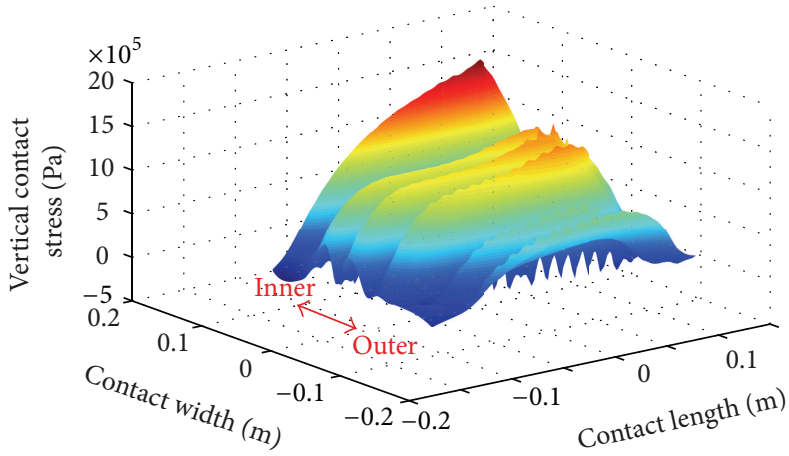

(a)

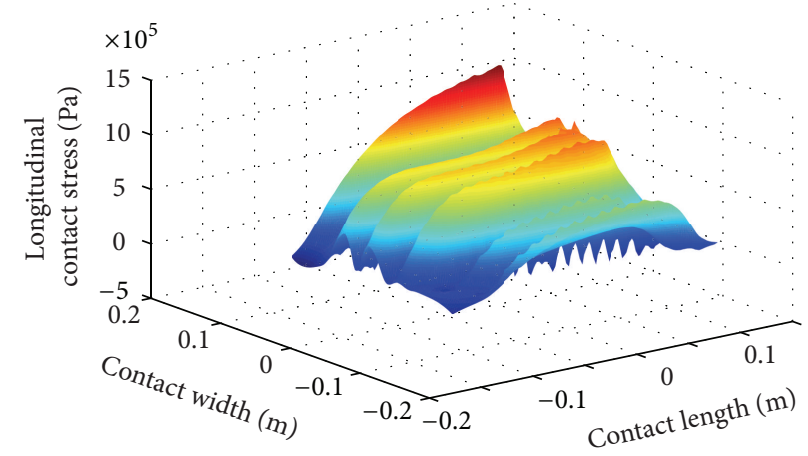

(b)

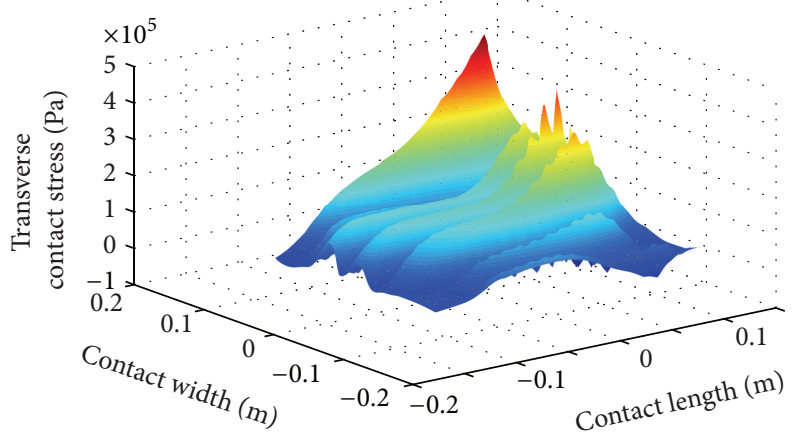

(c)

FIGURE 16: Contact stress distribution under braking condition with slip.

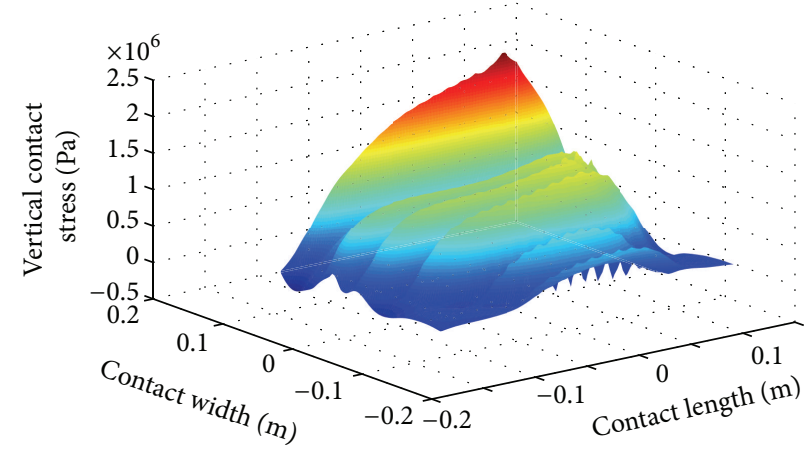

(a)

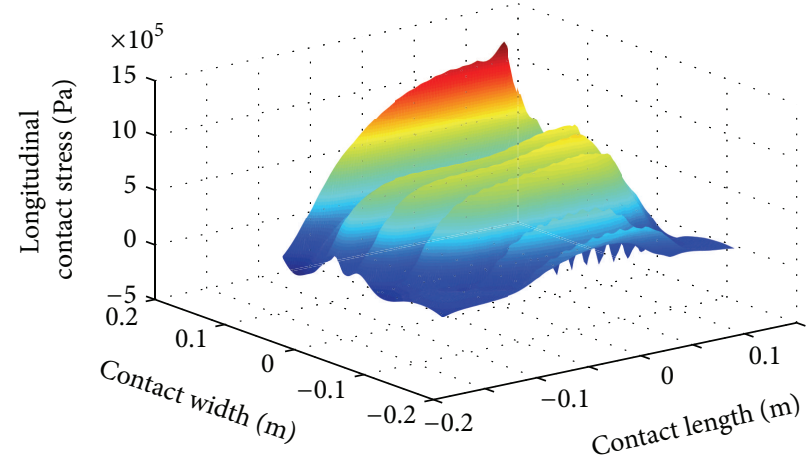

(b)

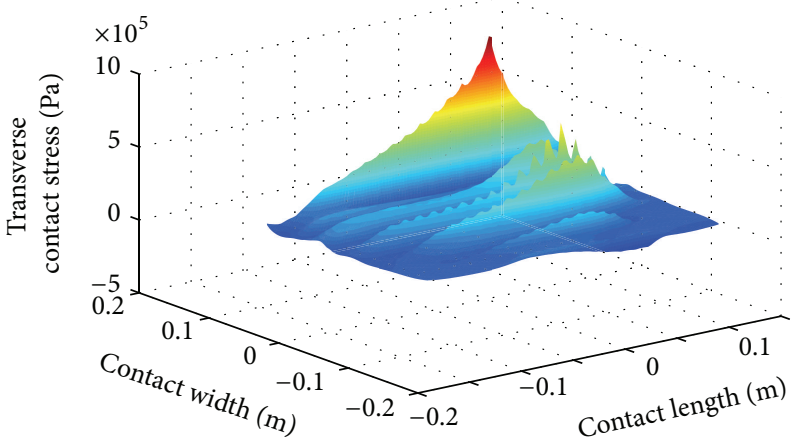

(c)

FIGURE 17: Contact stress distribution under braking condition combined with camber and slip. 
symmetric and maximum stress in free rolling state is less than that in the static state.

(3) The stress in the front of the contact area is much greater than that at the end region. Compared with the stress distribution in static and free rolling state, stress tends to increase from three directions. In particular, the change of longitudinal stress is the most obvious, from the raise at the front end and depression at the rear end, to rise in the entire contact area. The transverse stress moved to the front end, and the longitudinal stress vector in the ground is no longer zero. There is a braking force between the tire and the road surface.

(4) The contact stress distribution is greatly influenced by camber angle, side slip, the combined camber, and slip condition during braking. Under combined effects, the contact stress at the edge of shoulder is higher than that in the center rib. Compared with the effects under camber angle and slip angle separately, the stress distribution under combined working conditions moves towards the edge of the tire and the stress gap between tire shoulder and contact becomes larger. The sum of the contact stress vector in three directions is nonzero.

\section{Conflict of Interests}

The authors declare that there is no conflict of interests regarding the publication of this paper.

\section{Acknowledgment}

This work was supported by China National Funds for Young Scientists (Grant no. 51405201), Chinese Postdoctoral Science Foundation (Project no. 2015M571681), the Open Fund of Automotive Engineering Key Laboratory of Jiangsu Province, China (Project no. QC201303), and the Jiangsu University Advanced Talents Initial Funding Project (1291120046).

\section{References}

[1] Y.-J. Guan, G.-C. Zhao, and G. Cheng, "3-Dimensional nonlinear FEM modeling and analysis of steady-rolling of radial tires," Journal of Reinforced Plastics and Composites, vol. 30, no. 3, pp. 229-240, 2011.

[2] Y.-J. Guan, G.-C. Zhao, and G. Cheng, "FEA and testing studies on static camber performance of the radial tire," Journal of Reinforced Plastics and Composites, vol. 26, no. 18, pp. 1921-1936, 2007.

[3] S. Park, W. Yoo, J. Cho, and B. Kang, "Pressure-sensing pad test and computer simulation for the pressure distribution on the contact patch of a tyre," Proceedings of the Institution of Mechanical Engineers Part D: Journal of Automobile Engineering, vol. 221, no. 1, pp. 25-31, 2007.

[4] W. Wang, S. Yan, and S. Zhao, "Experimental verification and finite element modeling of radial truck tire under static loading," Journal of Reinforced Plastics and Composites, vol. 32, no. 7, pp. 490-498, 2013.
[5] H. Wang, I. L. Al-Qadi, and I. Stanciulescu, "Effect of surface friction on tire-pavement contact stresses during vehicle maneuvering," Journal of Engineering Mechanics, vol. 140, no. 4, Article ID 04014001, 2014.

[6] A. R. Savkoor, "Mechanics of sliding friction of elastomers," Wear, vol. 113, no. 1, pp. 37-60, 1986.

[7] V. Dorsch, A. Becker, and L. Vossen, "Enhanced rubber friction model for finite element simulations of rolling tyres," Plastics, Rubber and Composites, vol. 31, no. 10, pp. 458-464, 2002.

[8] B. Ma, H.-G. Xu, and H.-F. Liu, "Effects of road surface fractal and rubber characteristics on tire sliding friction factor," Journal of Jilin University Engineering and Technology Edition, vol. 43, no. 2, pp. 317-322, 2013.

[9] Z. Li, Z.-R. Li, and Y.-M. Xia, "Experimental and numerical study of frictional contact behavior of rolling tire," Journal of Shanghai Jiaotong University, vol. 47, no. 5, pp. 817-821, 2013.

[10] G. Heinrich and M. Klüppel, "Rubber friction, tread deformation and tire traction," Wear, vol. 265, no. 7-8, pp. 1052-1060, 2008.

[11] P. Baranowski, R. Gieleta, J. Małachowski, and Ł. Mazurkiewicz, "Rubber structure under dynamic loading-computational studies," Engineering Transactions, vol. 61, no. 1, pp. 34-46, 2013.

[12] X. Yang, O. A. Olatunbosun, and E. O. Bolarinwa, "Materials testing for finite element tire model," SAE International Journal of Materials and Manufacturing, vol. 3, no. 1, pp. 211-220, 2010.

[13] M. Gäfvert and J. Svendenius, "A novel semi-empirical tyre model for combined slips," Vehicle System Dynamics, vol. 43, no. 5, pp. 351-384, 2005.

[14] I. L. Al-Qadi and P. J. Yoo, "Surface tangential contact stresses effect on flexible pavement response," Journal of the Association of Asphalt Paving Technologists, vol. 76, pp. 663-692, 2007.

[15] J. J. Henry, Evaluation of Pavement Friction Characteristics, A Synthesis of Highway Practice. NCHRP Synthesis No. 291. National Cooperative Highway Research Program, Transportation Research Board, Washington, DC, USA, 2000.

[16] L. Li, F.-Y. Wang, and Q. Zhou, "Integrated longitudinal and lateral tire/road friction modeling and monitoring for vehicle motion control," IEEE Transactions on Intelligent Transportation Systems, vol. 7, no. 1, pp. 1-19, 2006. 

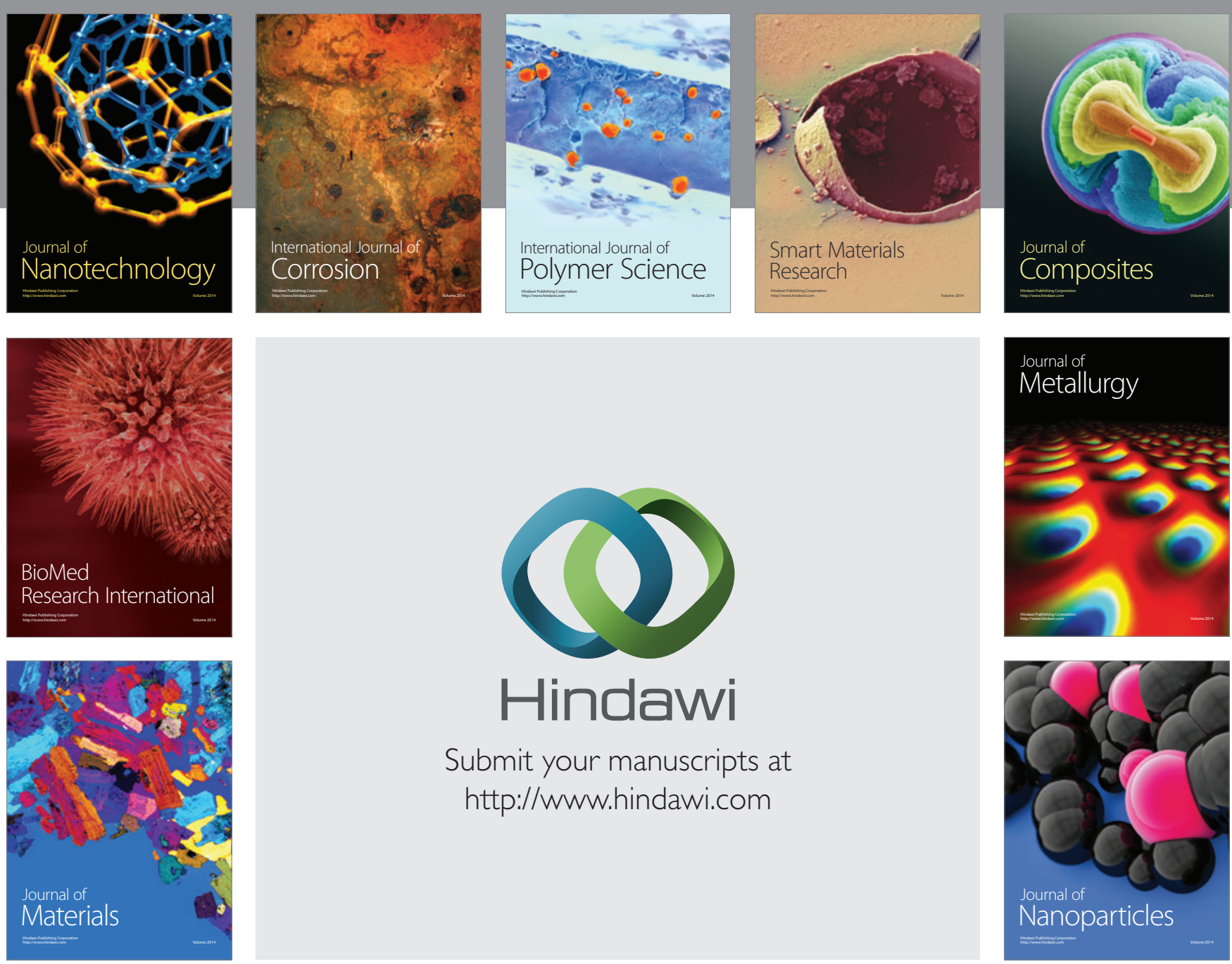

Submit your manuscripts at http://www.hindawi.com
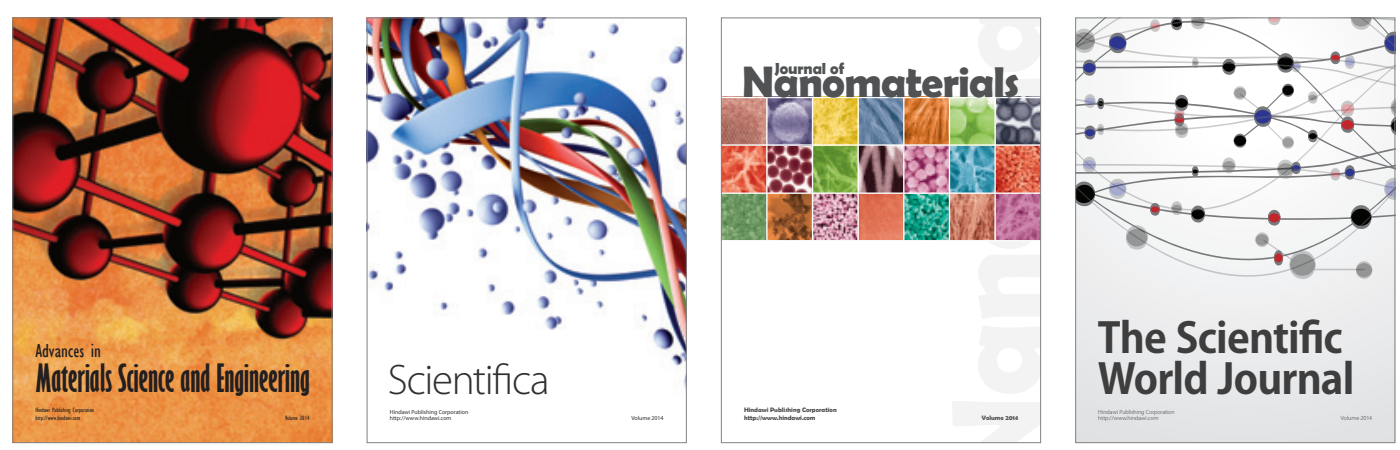

\section{The Scientific World Journal}
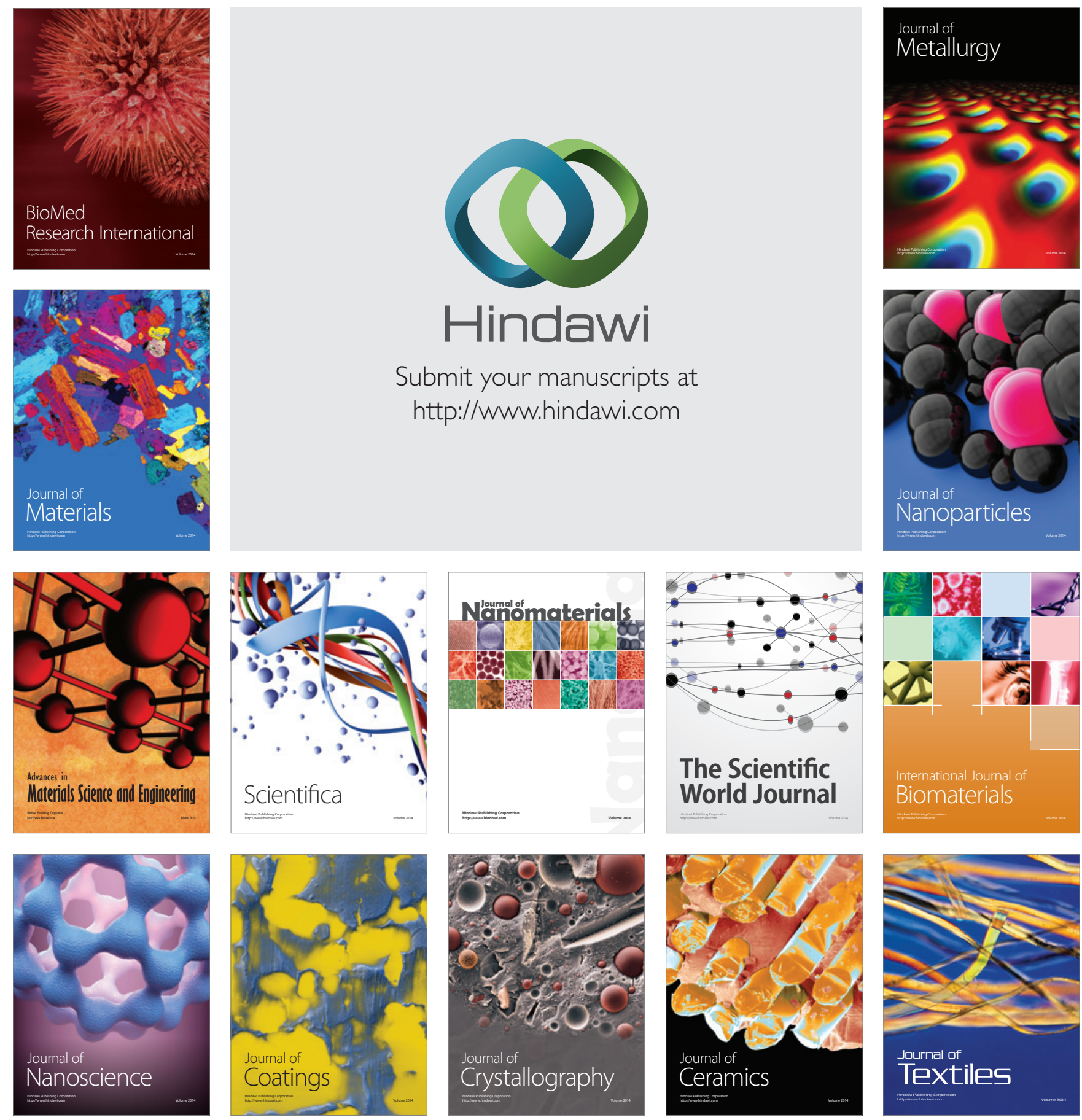